University of Nebraska - Lincoln

DigitalCommons@University of Nebraska - Lincoln

Publications, Agencies and Staff of the U.S.

Department of Commerce

U.S. Department of Commerce

2010

Stabilization of Fragments to Enhance Asexual Recruitment in Acropora Palmata, a Threatened Caribbean Coral

Dana E. Williams

NOAA-Fisheries, dana.williams@noaa.gov

Margaret W. Miller

NOAA-Fisheries

Follow this and additional works at: https://digitalcommons.unl.edu/usdeptcommercepub

Part of the Environmental Sciences Commons

Williams, Dana E. and Miller, Margaret W., "Stabilization of Fragments to Enhance Asexual Recruitment in Acropora Palmata, a Threatened Caribbean Coral" (2010). Publications, Agencies and Staff of the U.S. Department of Commerce. 330.

https://digitalcommons.unl.edu/usdeptcommercepub/330

This Article is brought to you for free and open access by the U.S. Department of Commerce at DigitalCommons@University of Nebraska - Lincoln. It has been accepted for inclusion in Publications, Agencies and Staff of the U.S. Department of Commerce by an authorized administrator of DigitalCommons@University of Nebraska - Lincoln. 
RESEARCH ARTICLE

\title{
Stabilization of Fragments to Enhance Asexual Recruitment in Acropora Palmata, a Threatened Caribbean Coral
}

\author{
Dana E. Williams ${ }^{1,2,3}$ and Margaret W. Miller ${ }^{2}$
}

\begin{abstract}
Historically, fragmentation has been a successful life history strategy in Acropora palmata. However, in areas where the population is sparse and degraded, the survivorship of fragments is now compromised. This study aimed to determine whether stabilization of A. palmata fragments could increase their overall performance. Naturally occurring fragments were found and assigned to one of three treatments: stabilized to the natural substrate (1) using cable ties, (2) using epoxy or (3) tethered to the substrate as an unstabilized control. After 44 weeks, the general "performance" of the fragments was ranked based on their
\end{abstract}

change in live tissue cover and formation of tissue connections with the substrate. Stabilized fragments lost less tissue cover and ranked higher in performance than the unstabilized control fragments. Stabilization using cable ties and epoxy were similarly effective. The results indicate that stabilizing fragments will preserve live tissue and enhance growth of fragments and can thus improve the survivorship of fragments.

Key words: acroporid, Biscayne National Park, Florida, restoration, reef.

\section{Introduction}

Acropora palmata (elkhorn coral), with its fast growth rate, branching morphology, and tendency to form dense monospecific stands (Goreau 1959; Bak et al. 1982; Miller et al. 2002a), performs keystone functions within Caribbean reef ecosystems by providing shelter to a variety of fish and other ecologically and economically important reef organisms (Lirman 1999), and accreting reef structure (Shinn et al. 1980). Since the 1970s, acroporid coral species in the Caribbean have experienced extreme and accelerating declines estimated at 90-98\% throughout their range (Bruckner 2002; Miller et al. 2002b). The severe and protracted population decline led the United States government to pursue the listing of $A$. palmata (along with its congener, Acropora cervicornis) as "threatened" under the U.S. Endangered Species Act in May 2005. This designation carries a legal mandate to plan and implement species recovery.

The life history of acroporid corals relies strongly on fragmentation and the successful recruitment (attachment to

\footnotetext{
${ }^{1}$ Cooperative Institute for Marine and Atmospheric Studies, RSMAS, University of Miami, 4600 Rickenbacker Causeway, Miami, FL 33149, U.S.A.

2 NOAA-Fisheries, SEFSC, 75 Virginia Beach Dr., Miami, FL 33149, U.S.A.

3 Address correspondence to Dana Williams, email dana.williams@noaa.gov
}

Published 2009. This article is a US Government work and is the substrate) of the fragments (Bothwell 1982; Highsmith 1982; Fong \& Lirman 1995; Lirman 2000). This reproductive strategy can foster rapid proliferation and spatial dominance; however, it can also result in losses because the loose fragments are more vulnerable to export or mortality (Lirman \& Fong 1996, 1997; Smith \& Hughes 1999). Once broken off of standing colonies, branch fragments may nestle into surrounding reef structures and reattach, or may be transported to sandy areas where they become abraded or smothered and eventually die (Bowden-Kerby 1997; Lirman \& Fong 1997; Smith \& Hughes 1999).

Successful recruitment of $A$. palmata fragments is severely hindered in the sparse A. palmata populations typically found in many locations. Recent evidence from degraded populations in the Florida Keys demonstrates that natural recruitment of A. palmata fragments in remnant stands is extremely low (Williams et al. 2008). Stands with low colony density do not retain fragments generated in storms as well as stands with more complex colony structure (Lirman \& Fong 1997; Miller et al. 2002a). Weakened skeletons resulting from increased bioerosion associated with degraded water quality (Ward-Paige et al. 2005) may result in more, smaller fragments that are more susceptible to export by waves (Highsmith et al. 1980; Lirman 2000). Although the benefits of fragmentation have historically outweighed the costs (Lirman 2000), the present depauperate state of Caribbean populations may have shifted the balance.

Current consensus recommendations to resource managers to promote conservation and recovery of this species include 
intervention by way of fragment attachment (Bruckner 2002; Acropora Biological Review Team 2005). As the population declines, proactive intervention (Edwards \& Clark 1998) through salvage of naturally-produced Acropora spp. fragments may be increasingly warranted.

Many fragment transplantation or reattachment projects have been undertaken, including many focusing on Acropora spp. However, the vast majority of these studies (Clark \& Edwards 1995; Smith \& Hughes 1999; Epstein et al. 2001; Lindahl 2003; Soong \& Chen 2003) have been with Indo-Pacific species (Nagelkerken et al. 2000). Those studies focused on Caribbean species have utilized A. cervicornis (Laydoo 1996; Bowden-Kerby 2001; Chilcoat 2004) rather than A. palmata. Because of the unique morphology of $A$. palmata (flat, relatively heavy branches), appropriate interventions would likely differ from those commonly used with staghorn-type Acropora spp. The few projects addressing A. palmata have been reported in fora relatively inaccessible to either scientists or managers (Garcia et al. 1995; Kaly 1995; Gilliam et al. 2000; Bezy \& Vasquez 2006) or lacked unrestored controls (Bruckner and Bruckner 2001; also Laydoo 1996) which are necessary for cost-benefit evaluation. Clearly, cost-benefit evaluation, both in absolute (i.e., benefit relative to no action) and relative terms (i.e., between different methods or practices) is required to appropriately allocate limited resources for species recovery.

This study evaluated whether stabilization of small, stormgenerated fragments of $A$. palmata resulted in increased growth and survivorship relative to unstabilized control fragments. We also compared the costs and performance of two simple methods of fragment attachment, that is, a marine epoxy and cable tying to reef substrate.

\section{Methods}

Acropora palmata fragments for this experiment were selected from those found naturally occurring at $3 \mathrm{~m}$ depth on Amanda's Reef $\left(\mathrm{N} 25^{\circ} 21.173^{\prime}, \mathrm{W} 80^{\circ} 10.682^{\prime}\right)$ in Biscayne National Park, Florida (USA). A total of 54 small $(<40 \mathrm{~cm})$ fragments were placed in wire baskets, brought to the surface, and transported to a small nearby ( $\sim 350 \mathrm{~m}$ north) but isolated patch reef $\left(\mathrm{N} 25^{\circ} 21.359^{\prime}, \mathrm{W} 80^{\circ} 10.656^{\prime}\right)$ for the experiment. Fragments were exposed to air for less than 10 minutes during the transfer.

Experimental fragments were photographed, the length was measured and the percentage of live tissue cover (on both sides) was visually estimated. Fragments were then grouped into 18 replicate experimental blocks of three with similar size and tissue coverage (Appendix 1). The three fragments in each block were then haphazardly allocated to one of three treatments: cable tied to the substrate (Fig. 1a-c), epoxied to the substrate (Fig. 1d-f), and an unstabilized control (Fig. 1g-i).

For both cable-tied and epoxied fragments, the substrate was prepared by scrubbing with a brush to remove sediment and macro algae. Positioning for the cable tied fragments was based on the availability of tunnels in the substrate to accommodate the cable tie. Fragments were then situated to maximize contact between the fragment and the substrate and secured with plastic cable ties (Fig. 1a). For epoxied fragments, All-fix epoxy (Cir-Cut Corporation, Philadelphia, PA, U.S.A.) was placed on already dead portions of the fragments when possible, but in cases where fragments were mostly or completely covered with live tissue, the epoxy was placed to maximize fragment stability regardless of the presence of live tissue (Fig. 1d).

Unstabilized fragments were included in each experimental block to provide an "unrestored" control. In a pilot attempt to follow loose A. palmata fragments at the experimental site, most migrated out of the area and could not be relocated. Thus, for this study, control fragments were tethered by attaching 1-m length of monofilament to each fragment using a cable tie and attaching the other end of the monofilament to the substrate using a nail and numbered tag (Fig 1g-i). The unstabilized fragment was placed on the substrate in a stable position relatively free from macroalgae or sediment deposits; however, the substrate was not scrubbed as this treatment was intended to simulate unmanipulated fragments. Tethering the control fragments provided a conservative comparison of the performance (relative to completely unmanipulated fragments) as they were still subject to abrasion and flipping over, but their overall distance of movement, and thus their potential for export to unsuitable habitat, was constrained.

Follow-up surveys were conducted to assess the condition and stability of the fragments at 7, 24, and 44 weeks following the initial setup in August 2006 (Appendix 2). During the first follow-up survey (week 7), epoxied or cable tied fragments that had become unstable were restabilized, but in later surveys no further manipulations were made. Only one epoxied fragment needed to be restabilized, but several of the cable ties needed to be tightened owing to settling of the fragments.

The treatments were evaluated based on change in live tissue, and tissue connection to the substrate (hereafter referred to as "connection"). Fragments were scored based on their condition at the final survey, 44 weeks after the setup. Both sides of the fragment were considered when assessing change in live tissue in order to account for tissue loss on the underside of the fragment that resulted from stabilization. Tissue on the undersides was assumed to be lost for all attached, stable fragments in all treatments. Control fragments that were still loose at the final survey were flipped to examine the bottom surface. Tissue connection to the substrate was scored as present once the tissue began to overgrow the adjacent natural reef substrate.

Within each blocked replicate, the "performance" of each treatment fragment was ranked from 1 (lowest) to 3 (highest). Fragments that displayed the greatest tissue growth and connection were ranked higher than those that lost live tissue and lacked tissue connection to the substrate. The fragments that were lost or died in place received the lowest rank within their representative blocks. Performance rank was compared 


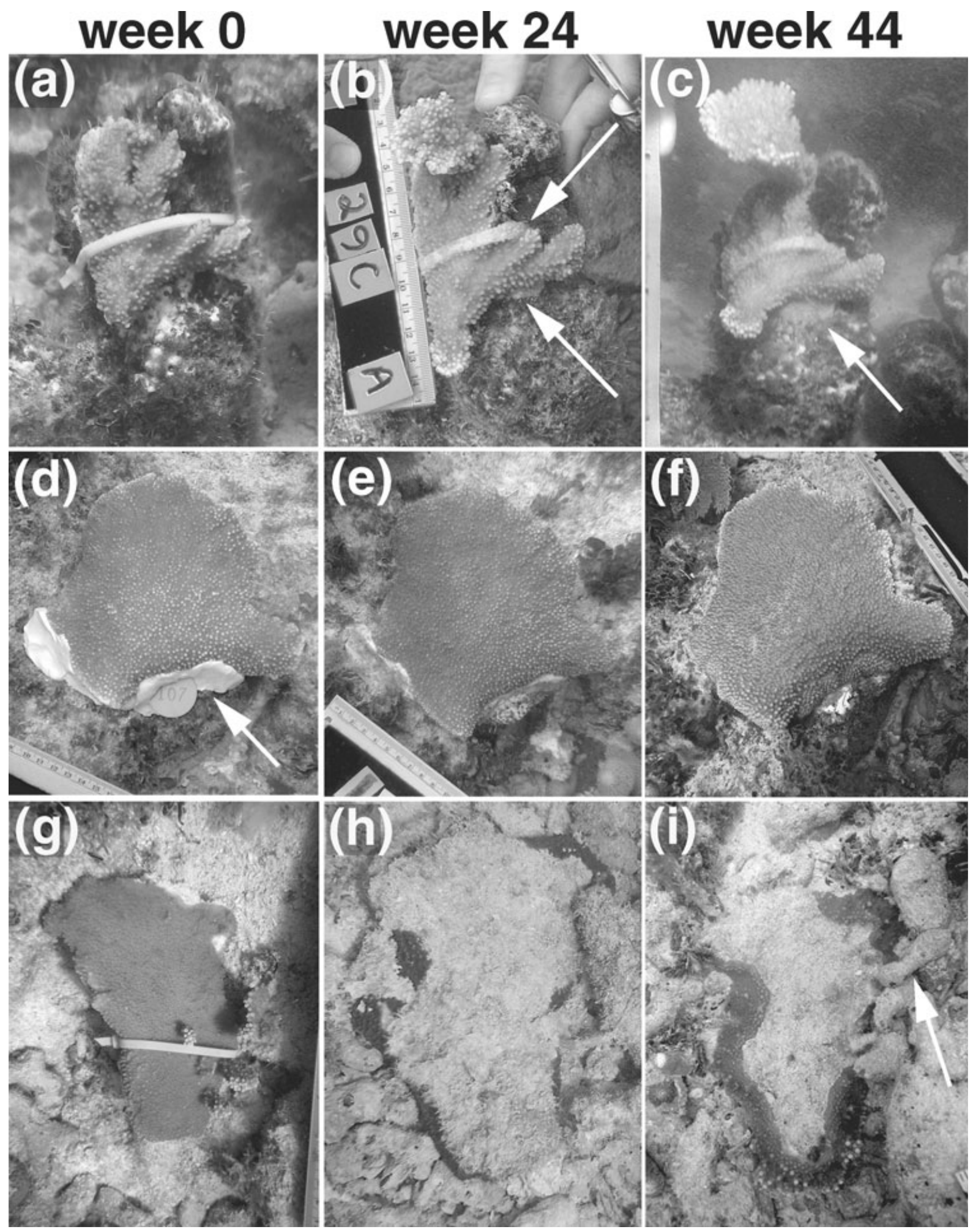

Figure 1. Time series for a typical cable tied $(a-c)$ and epoxy $(d-f)$ stabilized fragment and a tethered control (g-i). By week 24 (b) the cable tie on this fragment is completely overgrown, live tissue has formed an attachment with the substrate (see arrows) and a second protobranch has formed. By week 44 (c) substantial growth of the upper branch was observed. Note that tissue growth has occurred mostly at the branches compared with relatively minor resheeting of the dead skeleton (arrow). Epoxy was used directly on live tissue (d) in cases where no dead areas were present (arrow). No adverse tissue reaction was observed and tissue readily overgrew the epoxy (e-f). By week 24, this tethered fragment (g) had flipped over, burying most of the live tissue and exposing the dead underside (h) and formed small tissue connections to the substrate (not visible in figure). By week 44, the attachments were more robust and some growth of new tissue had begun (i). Note, however, that the attachments were formed with rubble (arrow), which could shift and loosen the fragment. 


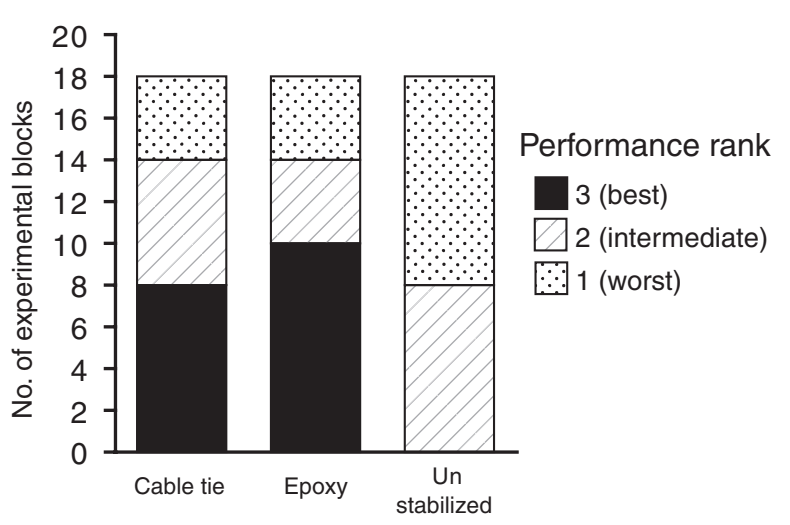

Figure 2. Counts of performance rank among the three treatments after 44 weeks. Performance was evaluated qualitatively based on tissue growth and connection with the substrate and ranked from 1 (lowest, including dead or lost) to 3 (highest) within each blocked replicate.

using a Friedman test, followed by a post-hoc comparison of the rank sums of all pairs (Conover 1980).

To test the hypothesis that initial live tissue cover (rather than experimental treatment) determined eventual success in making tissue connections, the control fragments were grouped into those that ultimately succeeded or failed to make a connection. The initial live tissue cover was compared between these two groups using a Mann-Whitney U test.

\section{Results}

At the start of the study, the A. palmata fragments ranged in length from 7 to $36 \mathrm{~cm}$ and in percent tissue cover between 15 and $95 \%$. Out of 54 total fragments, only one (in the cable tied treatment) suffered complete mortality in situ. Nine were physically lost from the experiment, of which five were tethered, two were epoxied and two were cable tied. These fragments were ranked as not attached and lowest in the performance scores.

Performance was significantly different among treatments ( $T=5.02, p<0.025$; Friedman test; Fig. 2). Epoxied and cable-tied fragments performed significantly better (one-tailed $\alpha / 2=0.025$ ) than unstabilized fragments but not significantly different from each other. There was no significant difference in the percent live tissue of the unstabilized fragments that made a connection compared to those that did not $(\mathrm{U}(7,6)=$ 15.5, $\mathrm{Z}=-0.79, p=0.43)$.

\section{Discussion}

\section{Tissue Loss and Growth}

Results indicate that stabilizing small, loose A. palmata fragments decreases the tissue that is lost during the natural attachment process (Garcia et al. 1995; Kaly 1995; Smith \& Hughes 1999). When fragments were stabilized using epoxy or cable ties, any live tissue on the underside of the fragment was lost due to shading or epoxy coverage. However, loose fragments lost tissue on both sides as a result of being flipped by wave action in the weeks or months that they were loose on the reef. This observation is different from those made in studies involving Acropora spp. with staghorn morphologies (Yap \& Gomez 1985; Bowden-Kerby 1997) but similar to those seen in other Acropora spp. with plate morphologies (Smith \& Hughes 1999) and is clearly a result of the flattened, two dimensional morphology of A. palmata (Highsmith 1982). Thus partial tissue loss is an inevitable consequence of the fragment recruitment process for platy acroporid species, but stabilizing the fragment stands to reduce the amount of tissue lost.

The stabilized fragments showed substantially greater growth as indicated by the ranked performance scores. In turn, this is expected to result in decreased time spent as smaller colonies, which are more vulnerable (Williams \& Miller 2006). Unstabilized fragments that failed to form connections but remained in place did not grow over the course of the experiment, suggesting that subsequent abrasion and/or the fragment's attempt to attach consumes physiological resources that would otherwise be available for growth (Bak 1983; Oren et al. 1997; Lindahl 2003).

\section{Connections and Stability}

Our qualitative observations indicate that the connections formed by the unstabilized fragments were less robust as they tended to settle in depressions alongside other loose material and subsequently attached to that loose material (Fig. 1). Thus, although they were considered "connected" to the substrate, the tissue connections appeared to be more tenuous than those formed in the stabilized treatments.

The initial percent live tissue cover (including both sides of the fragment) was not correlated to tissue connection for the unstabilized fragments. However, qualitative observations indicate that tissue connections to the substrate only occurred where the live tissue on the fragment margin contacted the substrate, regardless of the tissue presence on the remaining parts of the fragment. Thus, positioning the fragment to maximize the contact between a fragment's live edges and the substrate is crucial to the rapidity and success of its autonomous attachment.

\section{Recommendations}

While stabilization greatly improved performance, the method used for stabilization did not notably affect performance. Given the lack of an obvious "best" method we were able to conclude that both methods were appropriate for stabilizing fragments. However, we were able to identify some criteria to determine the method that might be most effective depending on various conditions.

When stabilizing the fragments for this study we found that cable ties were generally less applicable in that they require a position on substrate with a tunnel or branch around which to loop the cable tie. Additionally, if the substrate is heavily bioeroded, the added stress of tightening a cable tie may cause the substrate to break off along with the "stabilized" fragment. However, cable ties are more readily available and cost far less 
than epoxy, making them more practical in many situations. It should be noted that prior studies have used a nail as an attachment point for cable ties with marginal success (Kaly 1995; Bruckner \& Bruckner 2001).

Epoxy was suitable for a wider variety of substrate configurations and fragment shapes than cable ties. We were initially concerned that the epoxy might fail to adhere when applied directly to live tissue and that the contact would be harmful to adjacent live tissue. However, we observed that the epoxy performed very well and had no apparent harmful effect on the tissue (Fig. 1). In fact, the epoxy was rapidly colonized by turf and crustose coralline algae, and was readily overgrown by $A$. palmata tissue.

The epoxy used in this study (All-fix) is mixed in equal parts by hand and must be used within 15-20 minutes of mixing for the bond to be successful. As a result it is more labor-intensive and somewhat impractical for large $(>50 \mathrm{~cm})$ fragments. Epoxy is also difficult to use in high surge habitats because it may not set quickly enough (Appendix I in Bruckner 2002). Our study was setup in mild surge and the epoxy was able to cure; and once cured, our site experienced rough seas on many occasions. Only two epoxied fragments were dislodged and these failures were more likely owing to poor mixing/curing of the epoxy as their removal was observed early in the experiment and not coinciding with a rough weather period. All-fix epoxy used in similar applications has been observed to maintain its integrity for more than 5 years (K. Nedimyer 2009, Coral Restoration Foundation, Key Largo, FL, personal communication) which is ample time for fragments to form direct attachment to the substrate and overgrow the epoxy.

The success of fragments (stabilized or otherwise) likely depends on the potential exposure to subsequent disturbances, and the qualities of the surrounding habitat (Lirman \& Fong 1997; Nagelkerken et al. 2000; Miller et al. 2002a). These factors should be taken into consideration in determining an appropriate course of action after a fragmentation event. Fragments formed in structurally complex habitats are more likely to be retained (Lirman \& Fong 1997; Miller et al. 2002a) and recruit naturally in spite of disturbances, so intervention may not be warranted (Edwards \& Clark 1998). Larger fragments (Highsmith et al. 1980; Lirman 2000) and those surrounded by hard reef structure (Miller et al. 2002b) are less vulnerable to export to unsuitable areas; thus, stabilization may not substantially improve their performance. On the other hand, stabilization of smaller fragments and those with sparse coverage of live tissue may result in dramatic increases in their survivorship and growth.

Acropora palmata's life history, with proliferation highly dependent on successful fragmentation, is well suited to a highly abundant species, but because it is no longer highly abundant, this strategy has become a liability. With apparently low success in fragment recruitment (Williams et al. 2008), the tendency to fragment from natural or anthropogenic disturbances may now present more of a threat than a benefit for the remaining A. palmata population. Although other substantial threats exist, mitigating this one threat through simple and effective stabilization methods may improve the prognosis for this threatened species.

\section{Implications for Practice}

- Fragment stabilization/rescue is particularly beneficial when the loose fragments are at greater risk of removal from suitable reef structure. This risk is a function of both reef topography and the likelihood of subsequent physical disturbance.

- Stabilization of A. palmata fragments increases tissue survival and growth.

- Both epoxy and cable ties proved to be suitable for the stabilization of small A. palmata fragments. The choice between these two methods is determined by the configuration of the reef substrate, and access to materials.

- Marine epoxy can be safely used in contact with or adjacent to live A. palmata tissue.

- Positioning of the fragment is crucial to success: regardless of stabilization, direct contact between live tissue around the margins of the fragment and the reef substrate enhances tissue connection rate and stability of the fragment.

\section{Acknowledgments}

This study was supported by Biscayne National Park and the NOAA Coral Reef Conservation Program and conducted with express permission from park managers. Field assistance was provided by Lindsey Kramer, Rebecca Cassotis, and Chris Tilghman. Consultation by Amanda Bourque is greatly appreciated.

\section{LITERATURE CITED}

Acropora Biological Review Team. 2005. Atlantic Acropora Status Review Document. Report to National Marine Fisheries Service, Southeast Regional Office. March 3, 2005.

Bak, R. P. M. 1983. Neoplasia, regeneration and growth in the reef-building coral. Acropora palmata. Marine Biology 77:221-227.

Bak, R. P. M., S. R. Criens, and J. A. Marsh, Jr. 1982. Survival after fragmentation of colonies of Madracis mirabilis, Acropora palmata and A. cervicornis (Scleractinia) and the subsequent impact of a coral disease. Proceedings of the 4th International Coral Reef Symposium 2: 221-227. Manila, Philippines.

Bezy, B., and O. E. Vasquez. 2006. Large-scale (300 Colony) transplantation of healthy Acropora palmata colonies in Boca Chica, Dominican Republic: a possible control for remediation projects. Proceedings of the 10th International Coral Reef Symposium Abstracts 376. Okinawa, Japan.

Bothwell, A. M. 1982. Fragmentation, a means of asexual reproduction and dispersal in the coral genus Acropora-a preliminary report. Proceedings of the 4th International Coral Reef Symposium 1:137-144.

Bowden-Kerby, A. 1997. Coral transplantation in sheltered habitats using unattached fragments and cultured colonies. Proceedings of the 8th International Coral Reef Symposium 2:2063-2068.

Bowden-Kerby, A. 2001. Low-tech coral reef restoration methods modeled after natural fragmentation processes. Bulletin of Marine Science 69:915-931. 
Bruckner, A. W. 2002. Proceedings of the Caribbean Acropora Workshop. Potential application of the U.S. Endangered Species Act as a conservation strategy: April 16-18, 2002, Miami, Florida. NOAA Technical Memorandum. NMFS-OPR-24. Silver Spring, Maryland.

Bruckner, A. W., and R. J. Bruckner. 2001. Condition of restored Acropora palmata fragments off Mona Island, Puerto Rico, 2 years after the Fortuna Reefer ship grounding. Coral Reefs 20:235-243.

Chilcoat, G. C. 2004. Growth and survival of transplanted Acropora cervicornis in relation to coral reef restoration. Masters. University of Georgia.

Clark, S., and A. J. Edwards. 1995. Coral transplantation as an aid to reef rehabilitation: evaluation of a case study in the Maldive Islands. Coral Reefs 14:201-213.

Conover, W. J. 1980. Practical Nonparametric Statistics. $2^{\text {nd }}$ edition. John Wiley, New York.

Edwards, A. J., and S. Clark. 1998. Coral transplantation: a useful management tool or misguided meddling? Marine Pollution Bulletin 37:474-487.

Epstein, N., R. P. M. Bak and B. Rinkevich. 2001. Strategies for gardening denuded coral reef areas: the applicability of using different types of coral material for reef restoration. Restoration Ecology 9:432-442.

Fong, P., and D. Lirman. 1995. Hurricanes cause population expansion of the branching coral Acropora palmata (Scleractinia): wound healing and growth patterns of asexual recruits. Marine Ecology 16:317-335.

Garcia, R. P. U., E. M. C. Alvarado, and A. Acosta. 1995. Colony regeneration and fragment transplantation of Acropora palmata (Cnidaria: Scleractinia) in the natural national Park of Corales del Rosario, Colombian Caribbean. Anales del Instituto de Investigaciones Marinas de Punta de Betin. Santa Marta 24:5-21.

Gilliam, D. S., R. E. Dodge, S. L. Thornton, W. Jaap, and J. Wheaton. 2000. Scleractinian coral reattachment success and recruitment on a shallowwater ship-grounding site in southeast Florida, USA. Diving for Science in the 21 st Century. : 19 .

Goreau, T. F. 1959. The ecology of Jamaican coral reefs: I. species composition and zonation. Ecology 40:67-90.

Highsmith, R. C. 1982. Reproduction by fragmentation in corals. Marine Ecology Progress Series 7:207-226.

Highsmith, R. C., A. C. Riggs, and C. M. Dantonio. 1980. Survival of hurricane-generated coral fragments and a disturbance model of reef calcification/growth rates. Oecologia 46:322-329.

Kaly, U. L. 1995. Experimental test of the effects of methods of attachment and handling on the rapid transplantation of corals. Technical Report No. 1. CRC Reef Research Centre Ltd., Townsville.

Laydoo, R. S. 1996. Coral transplantation in reef management at Buccoo reef, south-west Tobago. Caribbean Marine Studies 5:67-77.

Lindahl, U. 2003. Coral reef rehabilitation through transplantation of staghorn corals: effects of artificial stabilization and mechanical damages. Coral Reefs 22:217-223.

Lirman, D. 1999. Reef fish communities associated with Acropora palmata: relationships to benthic attributes. Bulletin of Marine Science 65:235-252.

Lirman, D. 2000. Fragmentation in the branching coral Acropora palmata (Lamarck): growth, survivorship, and reproduction of colonies and fragments. Journal of Experimental Marine Biology and Ecology 251: $41-57$.

Lirman, D., and P. Fong. 1996. Sequential storms cause zone-specific damage on a reef in the northern Florida Reef Tract: evidence from Hurricane Andrew and the 1993 storm of the century. Florida Scientist 59:50-64.

Lirman, D., and P. Fong. 1997. Patterns of damage to the branching coral Acropora palmata following Hurricane Andrew: damage and survivorship of hurricane-generated asexual recruits. Journal of Coastal Research 13:67-72.

Miller, M. W., I. B. Baums, D. E. Williams, and A. M. Szmant. 2002a. Status of Candidate coral, Acropora palmata, and its snail predator in the upper
Florida Keys National Marine Sanctuary: 1998-2001. NOAA Technical Memorandum. NMFS-SEFSC-479. Miami, Florida.

Miller, M. W., W. C. Jaap, M. Chiappone, B. Vargas Angel, B. D. Keller, R. B. Aronson, and E. A. Shinn. 2002b. Acropora corals in Florida: status, trends, conservation, and prospects for recovery. Pages 59-70 in A. W. Bruckner, editor. Proceedings of the Caribbean Acropora workshop: potential application of the U.S. Endangered Species Act as a conservation strategy: April 16-18, 2002 Miami, Florida. NOAA Technical Memorandum NMFS-OPR-24.

Nagelkerken, I., S. Bouma, S. Van Den Akker, and R. P. M. Bak. 2000. Growth and survival of unattached Madracis mirabilis fragments transplanted to different reef sites, and the implication for reef rehabilitation. Bulletin of Marine Science 66:497-505.

Oren, U., B. Rinkevich, and Y. Loya. 1997. Oriented intra-colonial transport of C-14 labeled materials during coral regeneration. Marine Ecology Progress Series 161:117-122.

Shinn, E. A., V. V. Salomonson, and P. D. Bhavsar. 1980. Geologic history of Grecian Rocks, Key Largo Coral Reef Marine Sanctuary. Bulletin of Marine Science 30:646-656.

Smith, L. D., and T. P. Hughes. 1999. An experimental assessment of survival, re-attachment and fecundity of coral fragments. Journal of Experimental Marine Biology and Ecology 235:147-164.

Soong, K., and T. A. Chen. 2003. Coral transplantation: regeneration and growth of Acropora fragments in a nursery. Restoration Ecology 11:62-71.

Ward-Paige, C. A., M. J. Risk, and O. A. Sherwood. 2005. Clionid sponge surveys on the Florida Reef Tract suggest land-based nutrient inputs. Marine Pollution Bulletin 51:570-579.

Williams, D. E., and M. W. Miller. 2006. Importance of disease \& predation to the growth \& survivorship of juvenile Acropora palmata \& Acropora cervicornis: a demographic approach. Proceedings of the 10th International Coral Reef Symposium 1:1096-1104.

Williams, D. E., M. W. Miller, and K. L. Kramer. 2008. Recruitment failure in Florida Keys Acropora palmata, a threatened Caribbean coral. Coral Reefs 27:697-705.

Yap, H. T., and E. D. Gomez. 1985. Growth of Acropora pulchra III. Preliminary observations on the effects of transplantation and sediment on the growth and survival of transplants. Marine Biology 87:203-209.

\section{Supporting Information}

Additional Supporting Information may be found in the online version of this article:

Appendix 1. Fragments were grouped into experimental blocks of three fragments with similar size and live tissue cover (condition) as illustrated by the two blocks shown.

Appendix 2. Time series of a complete experimental block showing the performance of all three treatments over time. The loose fragment flipped over and lost most of its live tissue before week 7; by week 44 it had not attached but showed some tissue growth and protobranch formation. The cable-tied treatment had formed tissue attachments to the substrate by week 24 . It also began to resheet the older dead portions and developed numerous branches by week 44 . The epoxy treatment began overgrowing the epoxy by week 7 and new tissue extended down to the natural substrate by week 44. Most new tissue growth occurred in 1 main branch. The fragments in this block were ranked for performance (from low to high) as loose, epoxy then cable tie. The performance of the epoxy and cable tie treatment could be considered approximately equal but in the end the cable tie treatment was ranked higher due to the numerous robust attachment points that were formed. While the loose treatment in this case did not attach to the substrate it should be noted that the growth and branching displayed were not typical of other loose replicates.

Please note: Wiley-Blackwell is not responsible for the content or functionality of any supporting materials supplied by the authors. Any queries (other than missing material) should be directed to the corresponding author for the article. 